\title{
Anatomical and Imagistic Aspects of the Aortic Arch in Chinchilla lanigera
}

\author{
Cristian Martonos', Radu Lăcătuș', Daniel Cocan², Florin Stan', \\ Aurel Damian', Teodor Stroe' ', Cristian Dezdrobitu' \& Alexandru Gudea'
}

\begin{abstract}
Background: The investigation on the cardiocirculatory system in chinchilla has become increasingly important due to the use of the species in experimental medicine (toxicology, pathology, parasitology etc.). Even though initially this species was regarded with a strict economic interest, in the last period, chinchillas have become an increasingly-encountered patient in veterinary clinics and hospitals. Another aspect is the use of the species in medical research, as experimental model or in parasitology. The present study tackles a combined anatomical and radiological (angiographical) study to accurately describe the vascular anatomy of the initial part of the aortic arch (Arcus aortae).

Materials, Methods \& Results: The anatomical distribution of collaterals detached from arcus aorticus (brachiocephalic trunk and subclavian arteries) are highlighted in this paper. To do that, the classical stratigraphic anatomical investigation, followed by the radiological study with the help of the contrast substance injected into the vascular bed were used in combination. Several Chinchilla lanigera female carcasses, obtained from a private commercial farming unit in Cluj county, Romania were used for this study. Ten carcasses were used for the anatomical study, being injected into the vascular bed with a mixture of latex and acrylic dye, fixated into formaldehyde 5\% and later dissected, while the other ten carcasses were injected at the level of the aortic arch with Visipaque 320 contrast substance and subjected to the angiographical procedure.The anatomical investigation was carried after an initial 5 day-fixation period, while the angiographic procedure was initiated using the TEMCO Grx-01 device and the Veterinary Digital Imaging System ${ }^{\circledR}$ as digital imaging processing software. This combined study shows the differential mode of emergence of the subclavian and carotid arteries in this species. The brachiocephalic trunk is the first large collateral branch arising from the initial part of the aortic cross while the left subclavian artery, in all studied cases, stems from this initial part of the aortic arch. The right subclavian artery arises from the terminal part of the brachiocephalic trunk, at the cranial border of the first rib. The continuation of the trunk is represented by right common carotid artery that follows the right jugular groove. The left common carotid artery emerges at the medial aspect of the first intercostal space as a collateral branch detached from the brachiocephalic trunk, in its initial sector. In respect to the collaterals emerging from the subclavian arteries, our study showed that in all studied cases, four branches arise in sequence- the internal thoracic, dorsal scapular, vertebral and superficial cervical arteries. The existence of the common trunks (internal thoracic, dorsal scapular arteries and superficial and deep cervical arteries (as described by other authors) was not confirmed on the investigated specimens.

Discussion: The paper highlights some interesting facts referring to the specific morphology of the aortic arch in chinchilla, as literature data provides some divergent data. Some of the aspects noted are confirmed (the emergence of subclavian arteries) while some others are still subjects to discussion and further investigation (collateral branches of subclavian arteries). Our approach focuses also on the comparative aspects of the morphology of the branches emerging from the aortic arch. According to the available literature, the following species were used as comparison: leporids, Guinea pig, squirrel, yellow-necked mouse, Egyptian mouse, rat, armadillo, nutria, capybara, paca, fox and leopard.
\end{abstract}

Keywords: chinchilla, aortic arch, brachicephalic trunk, angiography, anatomy. 


\section{INTRODUCTION}

Chinchillas are small-sized rodents, belonging to the order Histricomorpha, family Chinchilidae, species Chinchilla. Their natural habitat is in the Andean mountains, 20-30 south latitude, in countries like Chile, Peru, Argentina and southern Bolivia. Even though initially this species was regarded with a strict economic interest (due to the fine textured fur and elegance), in the last period, the species has become an increasingly-encountered patient in veterinary clinics and hospitals as they are bred as pets. Another important aspect is the use of the species in medical research, chinchillas being an experimental model in middle otitis [10-12] or ototoxicity studies for certain substances $[1,6,12]$. Another worth-mentioning domain that focuses lately on the same species is parasitology $[5,16]$.

Studies on the cardiovascular system date a long time ago, starting from Antique Greece. Although the gross anatomy of the cardiovascular system in rodents is sufficiently described, in case of Chinchilla lanigera, specialty literature lacks certain descriptive data. To the best of our knowledge, methods with contrast substances were never used in this species.

The arterial vascularization of the heart was previously described [24] as well as digestive tube segments [23]. Other studies on the aortic arch in chinchilla were published later in 2004 and 2005 [2,28].

The present paper provides the study of the collateral branches given off from the aortic arch by means of the classical stratigraphic anatomical investigation, combined with the radiological study with the help of the contrast substance injected into the vascular bed and therefore to obtain morphological information that can justify a discussion in a functional perspective, resulting in support for the understanding the physiology of this species.

\section{MATERIALS AND METHODS}

\section{Animals}

The biological material was represented by 20 Chinchilla lanigera female carcasses originating from a private breeding facility from Cluj county, Romania, as the result of commercial slaughtering. Prior to slaughtering, all subjects were clinically monitored (pulse, respiration, body temperature) to ensure the clinically healthy state.

Dissection

After the slaughtering procedure and initial dissection, the identification of the aortic area was performed, flushing procedure with saline solution was performed and injection of the contrast substances was initiated. For 10 carcasses, a mixture of red acrylic dye $^{1}$ and latex ${ }^{1}$ was used (3:1) for later observation of the arteries of the cranial mediastinal space and neck while for the other ten carcasses (2nd lot), $5 \mathrm{~mL}$ of Visipaque $320^{2}$ (Odixanol) was injected.

The specimens from the 1 st lot were immersed in formaldehyde $5 \%$ and left for fixation for 5 days.

\section{Image procedure}

Next step was represented by the stratigraphical dissection, accompanied by anatomical recording and image capturing procedures. Schematic drawings were made initially with the help of magnifying glass for posterior recomposition of results in accordance to N.A.V. [13].

\section{Angiography procedure}

Specimens of the second lot were radiologically investigated, with the TEMCO Grx- $01^{3}$ device for the angiography procedure, using also the Veterinary Digital Imaging System $\AA^{4}$ for the processing of the digital files.

\section{RESULTS}

The first segment of the aorta, the ascending aorta (a. aorta ascendens), immediately after its emergence from the pericardic sack, slightly bends dorso-cranially to curve afterwards (in the precardiac mediastinum) in caudal direction. This section is known as the aortic arch or the aortic cross (arcus aortae) [4]. The data noted from the stratigraphic dissection and the radiographic ones show the fact that in area of the aortic cross in chinchilla, two collateral branches are emerging: the brachicephalic trunk ( $t r$. brachiocephalicus) and the left subclavian artery ( $a$. subclavia sinister) [Figures $1 \& 2$ ].

Known in speciality literature as the common brachiocephalic trunk (tr. brachiocephalicus commu$n i s)$, the artery detaches, in all investigated specimens of our study, as a collateral branch from the aortic cross at the level of the second intercostal space, to be orientated in cranial direction. Close to its origin, it gives off the common left carotid artery (a. carotis communis sinistra). From this level, the artery reaches the area of the first rib and splits terminally into the right subclavian artery (a. subclavia dextra) and the common right carotid artery (a. carotis communis dextra) [Figures 1 \& 2]. 


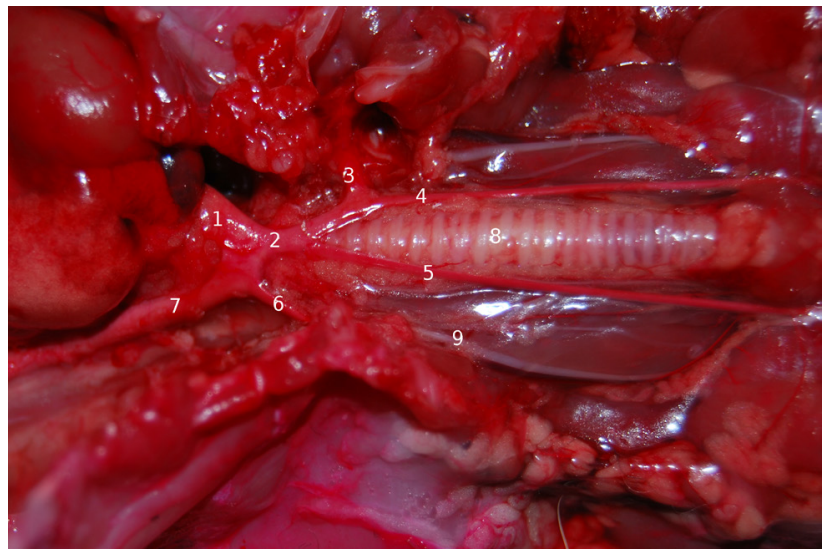

Figure 1. The aortic arch. 1. A. aorta ascendens; 2. Tr. brachiocephalicus 3. A. subclavia dexter; 4. A. carotis communis dexter; 5. A. carotis communis sinister; 6. A. subclavia sinister; 7. A. aorta descendens; 8. Trachea, 9. N. vagus.

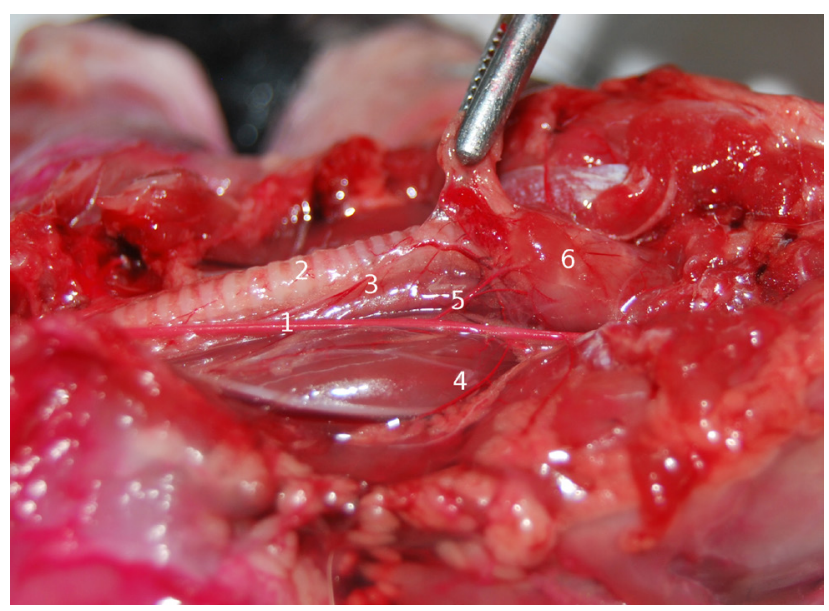

Figure 3. The left common carotid artery. 1. A. carotis comm sinistra, 2. Trachea, 3. Rami tracheale, 4. Rami musculari dorsale, 5. A. thyroidea, 6. Gl. Thyroidea.

The left common carotid artery (a. carotis communis sinistra) [Figure 3] emerges in an acute angle in the initial sector of the brachiocephalic trunk, at the medial aspect of the first intercostal space. Close to its origin, the artery is related to the ventral surface of the trachea, following a dorso-cranial trajectory on the ventro-lateral cervical part, reaching the area of the mandibular curvature.

The right common carotid artery (a. carotis communis dextra) [Figure 1] represents in fact the true continuation of the brachiocephalic trunk in cranial direction. From the point of splittage of the brachicephalic trunk, the artery heads dorso-cranially following the right jugular groove. Along their ascending pathway, the common carotid arteries give off tracheal branches, a cranial thyroidian artery and laryngeal branches (Figure 3). The caliber of both common carotid arteries seems to be uniform along

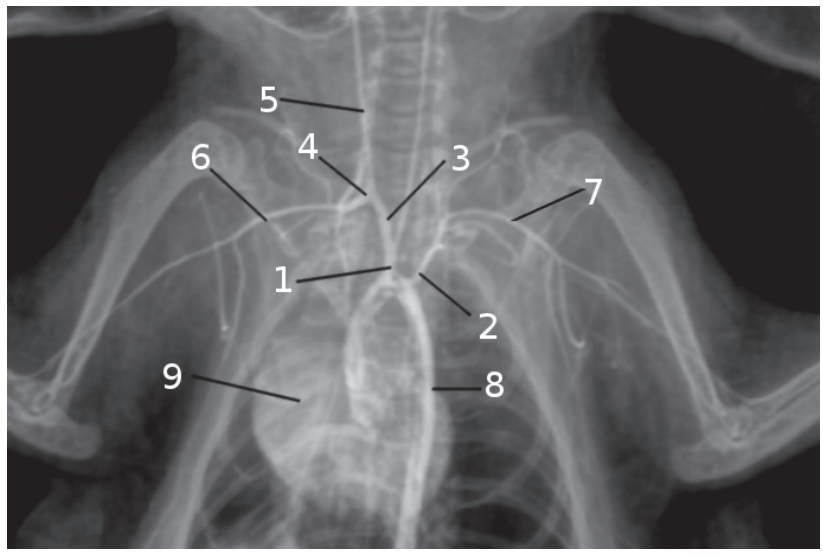

Figure 2. The aortic arch- imagistic aspects. 1. Tr. brachiocephalicus, 2. A. subclavia dexter, 3 . A. carotis communis sinister, 4. A. subclavia dexter, 5. A. carotis comunis dexter, 6. A. axilaris dexter, 7. A. axilaris sinister, 8 . A. aorta ascendens, 9. Cor.

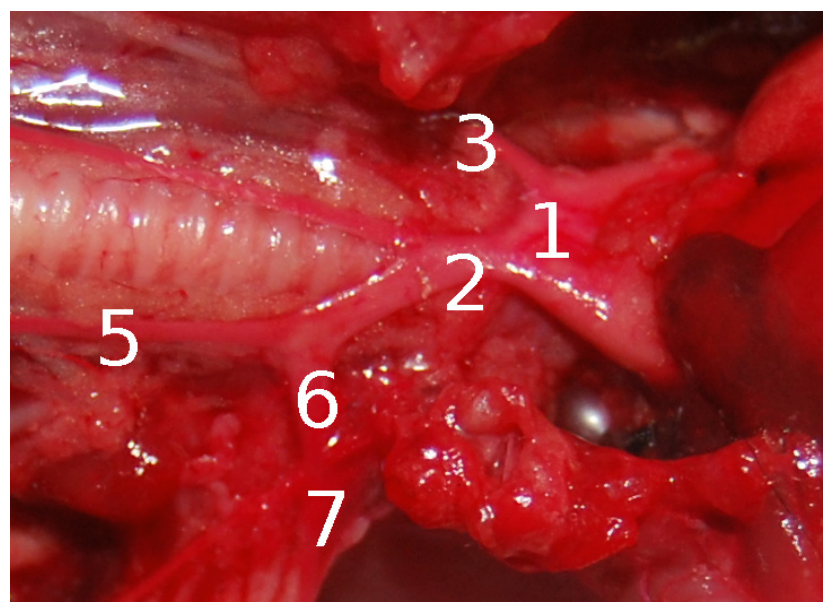

Figure 4. The subclavian arteries. Anatomical aspects. 1. Arcus aorticus, 2. Tr. brachiocephalicus, 3. A.subclavia sinistra, 4. A. carotis communis sinistra, 5. A. carotis communis dextra, 6. A. subclavia dextra, 7. A. axilaris dextra.

their trajectory, fact proved by the distribution of the contrast substance intraluminally and the uniform opaque appearance in captured images. The length, on the other hand, differs, the left common carotid artery being longer than the right one.

Similarly, in case of the two subclavian arteries, the origin is different. The left subclavian artery (a. subclavia sinister) [Figures $2 \& 4$ ] originates at the level of the cranial curvature of the aortic arch, representing, in fact, the second collateral emerging from this sector, after the brachicephalic trunk. The right subclavian artery (a. subclavia dexter) is one of the terminal branches of the brachicephalic trunk. From the point of their origin, the two subclavian arteries follow a medio-lateral course, reaching the cranial border of the first rib, terminating as the axillary arteries (aa. axilaris). Similarly to the situation observed in the common carotid arteries, the length of the left 


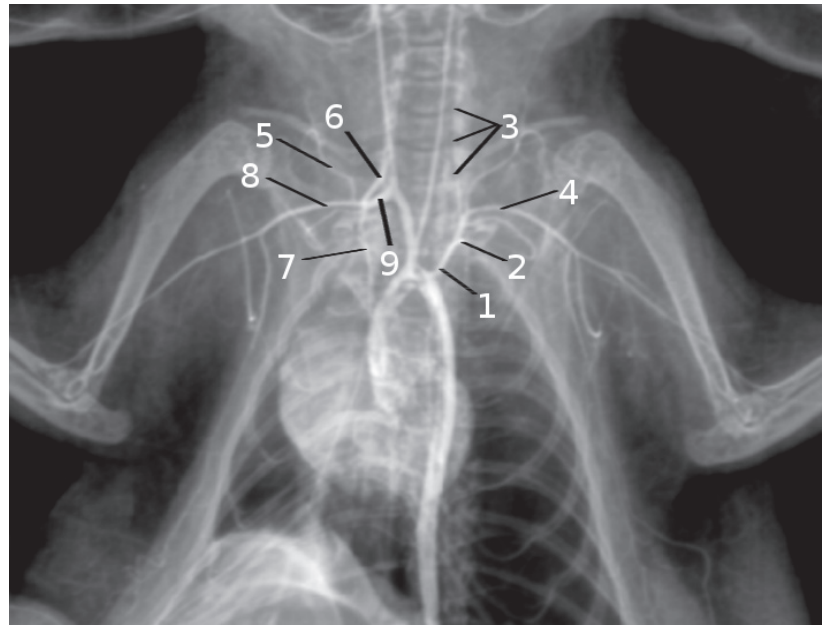

Figure 5. Subclavian arteries-imagistic aspects. 1. A. subclavicularis sinister, 2. A. thoracica interna sinister, 3. A. vertebralis, 4. A. axilaris, 5. A. scapularis dorsalis, 6. A. cervicalis superficialis, 7. A. intercostala suprema, 8. A. axilaris, 9. A. subclavicularis dexter.

subclavian exceeds the length of its counterpart (right subclavian artery).

Each subclavian artery emits four collateral branches. These are: the internal thoracic artery (a. thoracica interna), the dorsal scapular artery (a. scapularis dorsalis), the vertebral artery (a. vertebralis) and the superficial cervical artery (a. cervicalis superficialis) [Figure 5].

The internal thoracic artery (a. thoracica interna) arises from the caudal aspect of the subclavian artery, giving off, after a short trajectory the supreme intercostal artery (a. intercostalis suprema). From this point onwards, the internal thoracic artery continues caudally on the dorsal surface of the floor of the thoracic cavity [Figures $5 \& 6$ ], giving off the ventral intercostal branches (aa. intercostales ventrales), pectoral branches (rami perforantes), mammary pectoral branches (rami mammarii) and mediastinal branches (rami mediastinales).

The dorsal scapular artery (a. scapularis dorsalis) [Figures $5 \& 6$ ] is emitted dorsally. It leaves the thoracic inlet passing the cranial border of the first rib and distributes to the insterscapular region musculature. Terminally, the artery splits into a dorso-cranial branch (that distributes into $m$. spmispinalis and $m$. splenius) and a dorso-caudal branch (terminated into $m$. trapezius, pars thoracalis and $m$. longissimus).

The vertebral artery (a. vertebralis) [Figures $5 \& 6$ ] detaches from the dorsal surface of the subclavian artery, at the medial surface of the first rib. From its origin, the artery follows a dorso-cranial direction and leaves the thoracic inlet at the level of the cranial thoracic aperture. Once close to cervical vertebrae, it

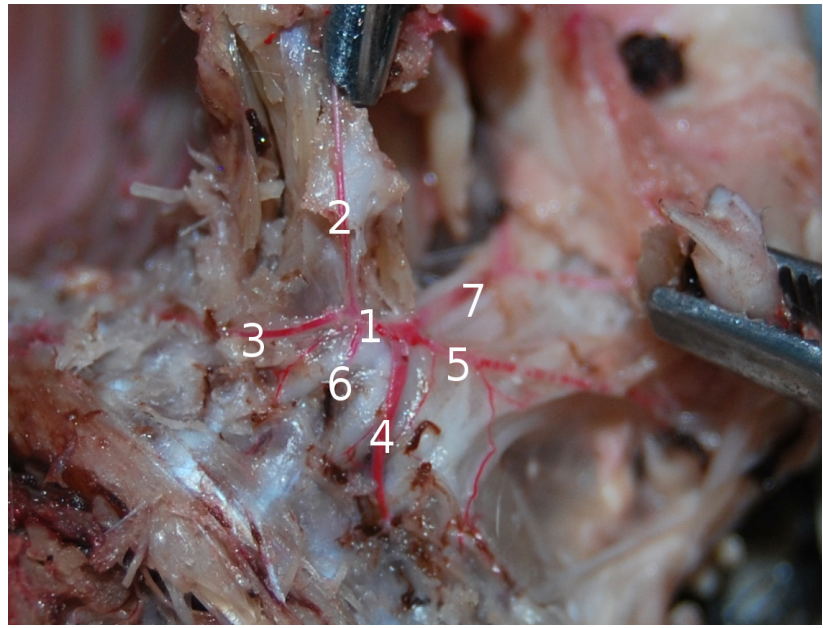

Figure 6. The collateral branches of the subclavian artery. Anatomical aspects. 1. A. subclavia, 2. A. thoracica interna, 3. A. intercostalis suprema, 4. A. vertebralis, 5. A. cervicalis superficialis, 6. A. scapularis dorsalis, 7. A. axilaris.

passes ventrally to the transverse process of C VII and passes through the transverse foraminae of the cervical vertebrae up to atlas.

The cervical superficial artery (a. cervicalis superficialis) [Figures $5 \& 6$ ] is the last collateral branch that detaches from the subclavian artery, following a cranio-lateral traject to ramify terminally into the superficial cervical muscular layers, reaching the shoulder area.

\section{DISCUSSION}

The angiography with contrast substance allows the in situ visualization of the trajectory and the distribution of the main arterial branches detached from the aortic arch in Chinchilla.

In terms of available literature, the aspects noted for the aortic arch and brachiocephalic trunk are slightly different from data reported by [28] but similar with the ones reported by $[2,22]$ in chinchilla [26], leporids [18,19], guinea pig [14,25], squirrel [3], fox [15], leopard [17] and paca [20].

The data obtained from our anatomical stratigraphical dissection and radiographic exposure reveal the fact that in chinchilla, the first collateral branch that detaches from the aortic arch is the brachiocephalic trunk, while the second is the left subclavian artery. Close to the cranial border of the first pair of ribs, the brachiocephalic trunk terminates in two branches- the right subclavian artery and the right common carotid artery.

Unlike chinchilla, in case of the egiptian mouse [21], rat [18], nutria [7] and armadillo [27], the aortic 
arch gives off three collaterals- the brachiocephalic trunk (tr. brachiocephalicus), left common carotid artery (a. subclavia sinister) and the left subclavian artery (a. subclavia sinister). Another particular situation is encountered in capybara [8], where the brachiocephalic trunk is the only collateral branch detached from the aortic cross. A similar situation was reported by in rabbit [26], guinea pig [25] and squirrel [3].

Different from this situation, in rat [21], mouse [18] and yellow-necked mouse [9], the left common carotid artery appears as a collateral branch of the aortic cross.

Some of the most significant data concluded by the study refer to the branches of the subclavian arteries. The situation encountered in studied chinchilla specimens differs slightly from the one described by other authors $[2,22]$ that state the existence of an initial common trunk in case of the internal thoracic artery and dorsal scapular artery and another trunk from which later the superficial and deep cervical arteries will be given off, same model being reported in case of the guineea pig [14], leporids [19,27] and paca [20].

\section{CONCLUSIONS}

The contrast substance angiographical method allows the better visualization in situ of the traject and distribution of main arterial branches emerging from the aortic arch in Chinchilla lanigera. The images of the stratigraphycal dissection and the ones obtained from the radiological investigation show that the first collateral branch given off from the aortic arch is the brachiocephalic trunk, the second being the left subclavian artery. In the close vicinity of the first pair of ribs, the brachiocephalic trunk divides, terminating as the right subclavian artery and the right common carotid artery.

\section{MANUFACTURERS}

${ }^{1}$ Amsterdam AllAcrylics. Apeldoorn, The Netherlands.

${ }^{2}$ GE Healthcare. Chicago, IL, USA.

${ }^{3}$ Tehno Electro Medical Company. Cluj-Napoca, Romania.

${ }^{4}$ ImageWorks Corporation. Elmsford, NY, USA.

Ethical approval. All applicable international, national, and/ or institutional guidelines for the care and use of animals were followed.

Declaration of interest. The authors declare that there is no conflict of interest that could be perceived as prejudicing the impartiality of the research reported.

\section{REFERENCES}

1 Al-Jarallah A., Akinpelu O. V., Citra D. \& Daniel S.J. 2012. Ototoxicity of baby oil in a chinchilla animal model. International Journal of Pediatric Otorhinolaryngology. 76(4): 564-568.

2 Araujo A.C.P., Oliveira J.C.D. \& Campos R. 2004. Collaterals branches of the aortic arch and its main rami in chinchila (Chinchilla lanigera). Revista Portuguesa de Ciências Veterinárias: 53-58.

3 Aydin A. 2011. The arteries originating from the aortic arch and the branches of these arteries in red squirrels (Sciurus vulgaris). Veterinarni Medicina. 56(3): 131-134.

4 Barone R. 1996. Anatomie comparée des mammifères domestiques. Tome cinquieme. Angiologie. Paris: Editions Vigot, 904p.

5 Basso W., Rütten M., Deplazes P. \& Grimm F. 2014. Generalized Taenia crassiceps cysticercosis in a chinchilla (Chinchilla lanigera). Veterinary Parasitology. 199(1-2): 116-120.

6 Bezdjian A., Mujica-Mota M.A., Azzi M. \&Daniel S.J. 2014. Assessment of ototoxicity of tea tree oil in a chinchilla animal model. International Journal of Pediatric Otorhinolaryngology. 78(12): 2136-2139.

7 Campos R., Araújo A.C.P. \& Azambuja R.C. 2010. Ramos colaterais do arco aórtico e suas principais ramificações em nutria (Myocastor coypus). Acta Scientiae Veterinariae. 38(2): 139-146.

8 Culau P.O.V., Reckziegel S.H., Lindemann T., Araújo A.C.P. \& Balzaretti F. 2007. Colaterais do arco aórtico da capivara (Hydrochoerus hydrochaeris). Acta Scientiae Veterinariae. 35(1): 89-92.

9 Eyison H.M., Kiralp S. \& Kivanc E. 2010. Apodemus flavicollis (Melchior, 1834) (Mammalia: Rodentia)'de Arcus Aortae'dan Köken Alan Damarlar. Veteriner Hekimler Derne i Dergisi. 81(2): 47-49.

10 Giebink G.S., Oberzins I.K., Marker S.C. \& Schiffman G. 1980. Experimental Otitis Media After Nasal Inoculation of Streptococcus pneumonie and Influenza A Virus in Chinchillas. Infection and Immunity. 30: 445-450.

11 Giebnik G.S. 1999. Otitis Media: The Chinchilla Model. Microbial Drug Resistance. 5(1): 57-72.

12 Hatomi M., Itahashi S. M., K., Nagura J., Fukushima T., Shimada J., Billal D.S., K.Yamauchi, Fujuhara K. \& Yamanaka N. 2007. Efficacy of a novel oral carbapenem, tebipenem pivoxil (TBM-PI), against experimental otitis media caused by penicillin resistant Streptococcus pneumoniae in chinchilla. Vaccine. 25: 2478-2484.

13 International Committee on Veterinary Gross Anatomical Nomenclature. 2017. Nomina Anatomica Veterinaria. 6th edn. Hannover: I.C.V.G.A.N., 160p. 
14 Kabak M. \& Haziroglu R.M. 2003. Subgross investigation of vessels originating from arcus aortae in guinea-pig (Cavia porcellus). Anatomia, Histologia, Embryologia. 32(6): 362-366.

15 Karakurum E. \& Özgel Ö. 2013. A macroanatomical study of the arcus aortae in the fox (Vulpes vulpes). Turkish Journal of Veterinary and Animal Sciences. 37(6): 672-674.

16 Maravilla P., Garza-Rodriguez A., Gomez-Diaz B., Jimenez-Gonzalez D.E., Toral-Bastida E., Martinez-Ocaña J., West B., Molina N., Garcia-Cortes R. \& Kawa-Karasik S. 2011. Chinchilla lanigera can be used as an experimental model for Taenia solium taeniasis. Parasitology International. 60(4): 364-370.

17 Martins D.M., Lima A.R., Pinheiro L.L., Silva S., Brígida D.S., Araújo E.B., Melul R., Carlos A., Lacreta Jr. A.C.C., Conceição A.M., Carla A., Souza B., Pereira L.C., Fioretto E.T. \& Branco É. 2010. Descricao morfologica dos ramos colateralis do arco aortico e suas principais ramificacoes em Leopardus pardalis. Acta Veterinaria Brasilica. 4: 74-77.

18 Maženský D., Petrovová E. \&Luptáková L. 2011. Variations in Origin of Arteries Supplying the Brain in Rabbit and Their Impact on Total Cerebral Ischemia Experiments. Folia Veterinaria. 55(4): 133-136.

19Okan E. \& Nejdet D. 2011. Yeni Zelanda Tav ani'nda (Oryctolagis cuniculus L.) arcus aortae ve ili kili dallarinin makroanatomisi. Veteriner Hekimler Derne i Dergisi. 82(2): 25-32.

20 Oliveira F.S., Machado M.R.F., Miglino M.A. \& Nogueira T.M.. 2001. Gross anatomical study of the aortic ARC branches of the paca (Agouti paca, Linnaeus, 1766). Brazilian Journal of Veterinary Research and Animal Science. 38(3): 103-105.

21 Oto C., Kiralp S., Eyison H.M., Kivanc E. \& Merih Haziroglu R. 2010. Subgross investigation of the blood vessels originating from aortic arch (Arcus aortae) in Spiny Mouse. Journal of Animal and Veterinary Advances. 9(20): 2665-2667.

22 Özdemir V., Çevik-Demirkan A. \& Türkmeno lu I. 2008. Subgross and Macroscopic Investigation of Blood Vessels Originating from Aortic Arch in the Chinchilla (Chinchilla lanigera). Anatomia, Histologia, Embryologia: Journal of Veterinary Medicine Series C. 37(2): 131-133.

23 Özdemir V., Çevik Demirkan A. \& Akosman M.S. 2013. Subgross and macroscopic investigation of the coeliac artery in the chinchilla (Chinchilla lanigera). Folia Morphologica. 72(3): 258-263.

24 Özdemir V., Çevik Demirkan A. \& Turkmenoglu I. 2008. The Right Coronary Artery is Absent in the Chinchilla (Chinchilla lanigera). Anatomia, Histologia, Embryologia: Journal of Veterinary Medicine Series C. 37(2): 114-117.

25 Parayani M.R., Gilanpour H., Aghili A.M., Rajaei S. M. \& Sadjadi R. 2012. Aortic arch in Guinea-Pig: The Macro anatomical Study. Annals of Biological Reasearch. 3(10): 4719-4722.

26Souza F., Bavaresco A.Z. \& Campos R. 2013. Ramos colaterais do arco aórtico e suas principais ramificações em coelho da raça Nova Zelândia (Oryctolagus cuniculus). Ciência Rural. 43(12): 2261-2267.

27 Souza W.M., Carvalhal R., Carvalho N.T.M., Miglino M.A. \& Carvalho R. 1996. Ramos do arco aortico no tatu peba (Euphractus sexcinctus). Veterinária Notícias. 2(1): 25-30.

28 Teke B., Eken E. \& Besoluk K. 2005. Study on Aortic Arch and its Arterial Branches in Chinchilla lanigera. Indian Veterinary Journal. 82: 1301-1303. 